Revista Tecné, Episteme y Didaxis: TED. Año 2014, Número Extraordinario. ISSN Impreso: 0121-3814, ISSN web: 2323-0126

Memorias, Sexto Congreso Internacional sobre Formación de Profesores de Ciencias. 08 al 10 de octubre de 2014, Bogotá

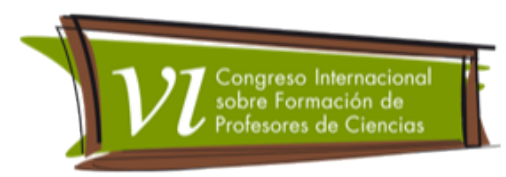

\title{
Novos Talentos na Educação Básica do Estado de Mato Grosso: inclusão, experimentações, descobertas
}

Kochhann Maria Elizabete Rambo', Negreiros Cláudia Landin²

\section{Resumo}

Este artigo apresenta resultados parciais de atividades realizadas no Projeto Descobrindo Talentos na Educação Básica nas Escolas de Mato Grosso, realizado em parceria com a Universidade do Estado de Mato Grosso - UNEMAT e nove escolas públicas dos municípios de Barra do Bugres, Nova Olímpia e Nortelândia. O projeto é fruto de políticas públicas educacionais implementadas pela Coordenação de Aperfeiçoamento de Pessoal de Nível Superior - CAPES, originado a partir de Programas Extracurriculares que investem em Novos Talentos da Rede Pública para Inclusão Social e Desenvolvimento da Cultura Científica. O objetivo principal é oportunizar aos estudantes de diferenciado desempenho acadêmico, e também de seus professores, possibilidades que cultivem a inovação, a descoberta, a curiosidade, o uso avançado das tecnologias de informação e comunicação.

\section{Palavras-chave}

Políticas Públicas Educacionais; Inclusão Social; Universidade; Educação Básica; Novos Talentos

\section{Introdução}

Sabe-se que a implementação de políticas públicas educacionais no Brasil e em muitos países tem ganhado espaço, em especial nas universidades, onde se realizam estudos, pesquisas e reflexões concernentes ao Estado em ação.

Nessa direção, expomos, neste artigo, resultados parciais de um projeto em andamento proposto pela Coordenação de Aperfeiçoamento de Pessoal de Nível Superior - CAPES. Trata-se do Programa Novos Talentos (EDITAL Nº55/2012) que apóia Projetos Extracurriculares, investindo em Novos Talentos da Rede Pública para Inclusão Social e Desenvolvimento da Cultura Científica.

\footnotetext{
1 Universidade do Estado de Mato Grosso - UNEMAT beterambo@gmail.com

2 Universidade do Estado de Mato Grosso - UNEMAT clnegreiros@unemat.br
} 
Revista Tecné, Episteme y Didaxis: TED. Año 2014, Número Extraordinario. ISSN Impreso: 0121-3814, ISSN web: 2323-0126

Memorias, Sexto Congreso Internacional sobre Formación de Profesores de Ciencias. 08 al 10 de octubre de 2014, Bogotá

Com o intuito de promover "[...] a valorização de espaços inovadores, tais como dependências de universidades, laboratórios e centros avançados de estudos e pesquisas, museus e outras instituições, inclusive empresas públicas e privadas." (BRASIL, 2012), o Projeto contempla subprojetos os quais apresentam, pelo menos, uma atividade relacionada à mobilidade no país voltada aos professores das escolas participantes.

Apoiando ações extracurriculares para professores e alunos da Educação Básica por meio de cursos, oficinas ou equivalentes, a proposta indica que as mesmas "[...] ocorram no período de férias das escolas públicas e/ou em horário que não interfira na frequência escolar." (Brasil, 2012).

No documento formulado pela agência financiadora há, ainda, a recomendação de que os projetos elaborados pelas Instituições Públicas de Ensino Superior (IPES) participantes devam apresentar um "[...] caráter inovador, visando aproximar os cursos de graduação e pós-graduação às escolas públicas." (BRASIL, 2012).

Dentre as ações que se caracterizam pela propositura de políticas públicas educacionais dessa natureza está o Projeto Descobrindo Talentos na Educação Básica nas Escolas de Mato Grosso, aprovado com quatro subprojetos que atendem a nove escolas dos municípios de Barra do Bugres, Nova Olímpia e Nortelândia, coordenado pela Universidade do Estado de Mato Grosso - UNEMAT - Campus de Barra do Bugres. Cabe mencionar que a proposta submetida foi idealizada por um grupo de professores dos diferentes cursos deste Campus, e conta também com o apoio e a participação das Secretarias de Estado (SEDUC MT) e Municipais de Educação onde se localizam as escolas atendidas.

Apresentamos, então, na sequência, a configuração desse Projeto no que concerne aos objetivos, subprojetos, cursos e suas respectivas metodologias, ações, e alguns resultados parciais.

\section{Objetivos}

Ao elaborarmos as atividades desenvolvidas no Projeto, procuramos alcançar os seguintes objetivos: 1. Oportunizar aos estudantes de diferenciado desempenho acadêmico e seus professores possibilidades que cultivem a inovação, a descoberta, a curiosidade, o uso avançado das tecnologias de informação e comunicação; 2. Criar espaços para a geração $Y$ desenvolver novas 
Revista Tecné, Episteme y Didaxis: TED. Año 2014, Número Extraordinario. ISSN Impreso: 0121-3814, ISSN web: 2323-0126

Memorias, Sexto Congreso Internacional sobre Formación de Profesores de Ciencias. 08 al 10 de octubre de 2014, Bogotá

competências básicas para a sua sobrevivência; 3. Ofertar cursos presenciais e em EAD aos alunos selecionados nas dependências da IES.

Com o intuito de oferecer aos professores dessas instituições a vivência de situações reais, nas quais se encontram temáticas referentes a cada um dos subprojetos, o Projeto propõe as seguintes atividades: 1) visita a uma indústria de reciclagem de lixo; 2) ida a uma universidade onde se desenvolvem propostas de inovação em sala de aula com o uso das Tecnologias de Informação e Comunicação; 3) visita a lugares históricos do Estado de Mato Grosso, tais como: a capital do Estado (Cuiabá), o município de Chapada dos Guimarães, o bioma Pantanal; 4) ida a universidades que oferecem programas de Pós-Graduação, com 0 intuito de despertar nesses professores o desejo de continuarem seus estudos em nível de mestrado ou doutorado.

\section{Referencial teórico}

Com a consolidação de programas dessa envergadura, a CAPES assume a responsabilidade para a qual fora idealizada por Anísio Teixeira em 1951, ou seja, a de possibilitar formação de pessoal para todos os níveis da Educação, inclusive da Educação Básica, sem qualquer prejuízo ao seu papel na qualificação do ensino superior, e com o compromisso do desenvolvimento científico e tecnológico do país. (Brasil, 2011).

Nessa direção, mas mostrando que ainda há muito a ser feito em políticas públicas educacionais, Xavier; Ribeiro; Noronha (1994, pág. 278) afirmam que:

Diante do quadro de profundas crises (política, econômica e social), - Estado procura instrumentos de aproximação e de incorporação das massas populares mostrando a "intenção" de diminuir as desigualdades e de assistir os despossuídos. A Educação passa a representar uma das estratégias destinadas a realizar a "justiça social."

É o caso dessa proposta, a qual busca a democratização e a qualidade da educação. Assim é que ao realizarmos ações extensionistas por meio de projetos dessa natureza, acreditamos estar em consonância com aqueles que buscam nas escolas.

Criar uma educação que reconheça e se oponha na prática às desigualdades sociais diversas, que ajude os alunos a investigarem 
Revista Tecné, Episteme y Didaxis: TED. Año 2014, Número Extraordinario. ISSN Impreso: 0121-3814, ISSN web: 2323-0126

Memorias, Sexto Congreso Internacional sobre Formación de Profesores de Ciencias. 08 al 10 de octubre de 2014, Bogotá

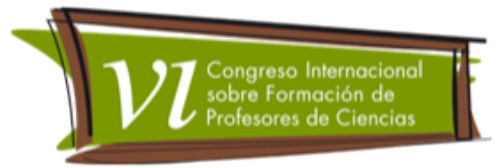

como seu mundo e suas vidas tornaram-se o que são e que considere seriamente $\mathrm{o}$ que pode ser feito para a alteração substancial disso tudo (Apple, 1996, pág. 108).

\section{Metodologia}

Antes de apresentarmos a metodologia que orienta o projeto em questão, elencamos, a seguir, os quatro subprojetos que o compõe: 1) Cidadania e os caminhos para a sustentabilidade; 2) TICs: Instrumentos de ensino e aprendizagem; 3) Histórias e memórias: conhecer e comunicar; 4) Universidade e escolas: parcerias fomentando o crescimento profissional.

Para o desenvolvimento das atividades com os alunos de cada uma das escolas foi necessário selecionar aqueles de melhor desempenho acadêmico. Outro critério é que esses estivessem nos anos finais de ciclo ou do ensino médio, além de manifestarem o desejo de participar. E mais, quanto aos professores, esses foram convidados pelos coordenadores do projeto a atuarem como parceiros nas atividades. Já em relação aos docentes da universidade, considerou-se a disponibilidade, o comprometimento, e a afinidade com ações extensionistas.

Terminada essa etapa, demos início a algumas atividades de dois subprojetos, as quais estão descritas no quadro a seguir:

Quadro 1 - Atividades desenvolvidas - Projeto Descobrindo Talentos na Educação Básica nas Escolas de Mato Grosso

\begin{tabular}{|c|c|c|c|}
\hline Local & Subprojeto & Atividade & Participantes \\
\hline $\begin{array}{l}\text { Aula de campo - } \\
\text { =azenda Arco Íris - } \\
\text { Barra do Bugres }\end{array}$ & $\begin{array}{l}\text { pubprojeto 3- Construindo uma } \\
\text { história: dos frutos da terra aos } \\
\text { lesafios da } \\
\text { ndustrialização. }\end{array}$ & $\begin{array}{l}\text { Verificar características } \\
\text { e peculiaridades das } \\
\text { Eulturas de soja e } \\
\text { Eana-de-açúcar }\end{array}$ & $\begin{array}{l}\text { Alunos das } \\
\text { professores da } \\
\text { hove escolas e da } \\
\text { jniversidade. }\end{array}$ \\
\hline $\begin{array}{l}\text { EE João } \\
\text { pobrinho e e EE Profa. } \\
\text { Francisca de } \\
\text { Alencar } \\
\text { Plímpia }\end{array}$ & $\begin{array}{l}\text { pubprojeto } 3 \text { - Construindo uma } \\
\text { história: dos frutos da terra aos } \\
\text { plesafios da industrialização. }\end{array}$ & $\begin{array}{l}\text { Detalhando } \\
\text { nformações não } \\
\text { abordadas na aula de } \\
\text { Eampo. }\end{array}$ & $\begin{array}{l}\text { Alunos das } \\
\text { professores da } \\
\text { duas escolas e da } \\
\text { jniversidade. }\end{array}$ \\
\hline $\begin{array}{l}\text { Universidade do } \\
\text { Estado de Mato } \\
\text { Grosso - UNEMAT - }\end{array}$ & $\begin{array}{l}\text { pubprojeto 4- Através de } \\
\text { parcerias com as IES e Técnico, } \\
\text { promover visitas dirigidas às }\end{array}$ & $\begin{array}{lr}\text { Apresentação } & \text { dos } \\
\text { fursos } & \text { pelos } \\
\text { foordenadores } & \text { e }\end{array}$ & $\begin{array}{lr}\text { Alunos } & \text { e } \\
\text { professores } & \text { das } \\
\text { hove } & \text { escolas }\end{array}$ \\
\hline
\end{tabular}


Revista Tecné, Episteme y Didaxis: TED. Año 2014, Número Extraordinario. ISSN Impreso: 0121-3814, ISSN web: 2323-0126

Memorias, Sexto Congreso Internacional sobre Formación de Profesores de Ciencias. 08 al 10 de octubre de 2014, Bogotá

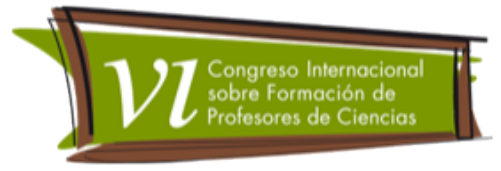

\begin{tabular}{|c|c|c|c|}
\hline $\begin{array}{l}\text { Eampus de Tangará } \\
\text { la Serra }\end{array}$ & $\begin{array}{l}\text { Iniversidades, Institutos e Escolas } \\
\text { écnicas. }\end{array}$ & $\begin{array}{l}\text { diretores } \\
\text { aculdades. }\end{array}$ & $\begin{array}{l}\text { parceiras e da } \\
\text { universidade. }\end{array}$ \\
\hline $\begin{array}{l}\text { Universidade do } \\
\text { Estado de Mato } \\
\text { Grosso - Campus de } \\
\text { Barra do Bugres }\end{array}$ & $\begin{array}{l}\text { pubprojeto 4- Através de } \\
\text { parcerias com as IES e Técnico, } \\
\text { promover visitas dirigidas às } \\
\text { Iniversidades, Institutos e Escolas } \\
\text { écnicas. }\end{array}$ & $\begin{array}{lr}\text { Apresentação } & \text { dos } \\
\text { fursos } & \text { pelos } \\
\text { foordenadores } & \text { e } \\
\text { diretores } & \text { das } \\
\text { aculdades. } & \end{array}$ & $\begin{array}{l}\text { Alunos e } \\
\text { professores das } \\
\text { hover escolas } \\
\text { parceiras e da } \\
\text { universidade. }\end{array}$ \\
\hline $\begin{array}{l}\text { EE Dr. Emmanuel } \\
\text { Pinheiro da Silva } \\
\text { primo e EE Des. } \\
\text { plegário Moreira de } \\
\text { Barros - Nortelândia }\end{array}$ & $\begin{array}{l}\text { pubprojeto 4- Através de } \\
\text { parcerias com as IES e Técnico, } \\
\text { promover visitas dirigidas às } \\
\text { Iniversidades, Institutos e Escolas } \\
\text { écnicas. }\end{array}$ & $\begin{array}{l}\text { Apresentação dos } \\
\text { fursos e profissões } \\
\text { eitas por professores e } \\
\text { jessoas } \\
\text { fomunidade } \\
\text { alunos }\end{array}$ & $\begin{array}{l}\text { Alunos das duas } \\
\text { escolas. }\end{array}$ \\
\hline $\begin{array}{l}\text { E Dr. Emmanuel } \\
\text { Pinheiro da Silva } \\
\text { primo e EE Des. } \\
\text { plegário Moreira de } \\
\text { Barros - Nortelândia }\end{array}$ & $\begin{array}{l}\text { pubprojeto 3- Construindo uma } \\
\text { história: dos frutos da terra aos } \\
\text { plesafios da industrialização. }\end{array}$ & $\begin{array}{l}\text { Detalhando } \\
\text { nformações não } \\
\text { abordadas na aula de } \\
\text { Eampo }\end{array}$ & $\begin{array}{l}\text { Alunos } \\
\text { professores das } \\
\text { duas escolas e da } \\
\text { jniversidade. }\end{array}$ \\
\hline $\begin{array}{l}\text { Ehapada } \\
\text { Guimarães - MT }\end{array}$ & $\begin{array}{l}\text { pubprojeto 3- Vivenciando a } \\
\text { história de Mato Grosso: } \\
\text { hatureza, sociedade e suas } \\
\text { diversidades }\end{array}$ & $\begin{array}{l}\text { Eaverna Aroé Jari, Véu } \\
\text { das noivas, Kiogo } \\
\text { Brado, Mirante, e } \\
\text { putros. }\end{array}$ & $\begin{array}{l}\text { Professores das } \\
\text { sscolas de } \\
\text { Nortelândia, Nova } \\
\text { blímpia, } \\
\text { pcadêmicos e } \\
\text { docentes }\end{array}$ \\
\hline
\end{tabular}

Organização: KOCCHANN, Maria Elizabete Rambo; 2013.

Para a realização dessas atividades, contamos com a participação dos funcionários e professores das escolas, os quais se responsabilizaram pelos preparativos, tais como: autorização de pais, agendamento de ônibus das prefeituras, etc.; a alimentação também está prevista nesses deslocamentos, como previsto no Edital.

Ressaltamos que todas as visitas são guiadas por especialistas da área, professores e docentes da universidade, e ocorrem extra-turno; já as viagens mais distantes ocorrem aos finais de semana.

Na sequência, algumas imagens dessas atividades com a participação de alunos, professores e docentes. 
Revista Tecné, Episteme y Didaxis: TED. Año 2014, Número Extraordinario. ISSN Impreso: 0121-3814, ISSN web: 2323-0126

Memorias, Sexto Congreso Internacional sobre Formación de Profesores de Ciencias. 08 al 10 de octubre de 2014, Bogotá

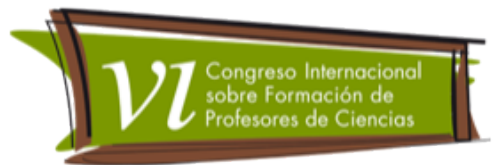

Figura 1 - Professores, alunos e docentes Fazenda Arco Íris - Barra do Bugres - MT 20/11/2013

Fonte: Maria Elizabete Rambo Kocchann, Acervo particular, 2013.

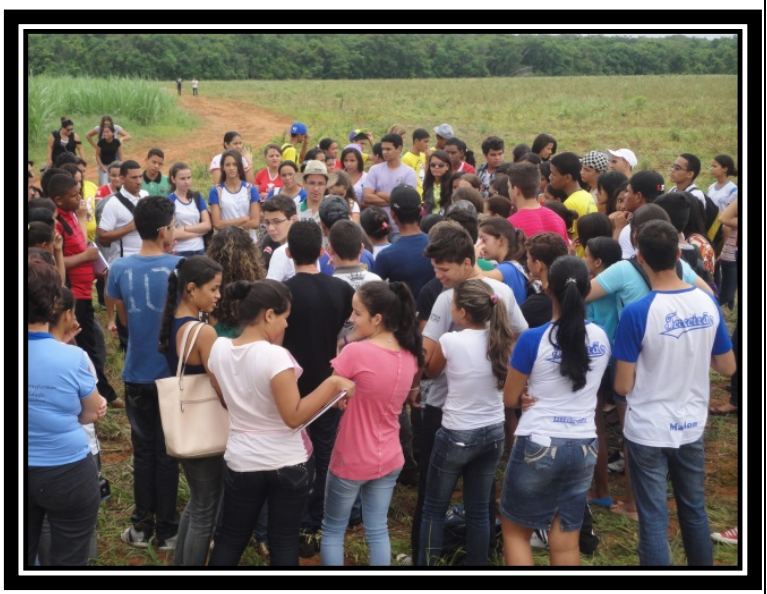

Figura 3 - Caverna Aroé Jarí - Chapada dos Guimarães - MT - 16/12/2013

Fonte: Maria Elizabete Rambo Kocchann, Acervo particular, 2013.
Figura 2 - Fazenda Arco Íris - Barra do Bugres MT $20 / 11 / 2013$

Fonte: Maria Elizabete Rambo Kocchann, Acervo particular, 2013.

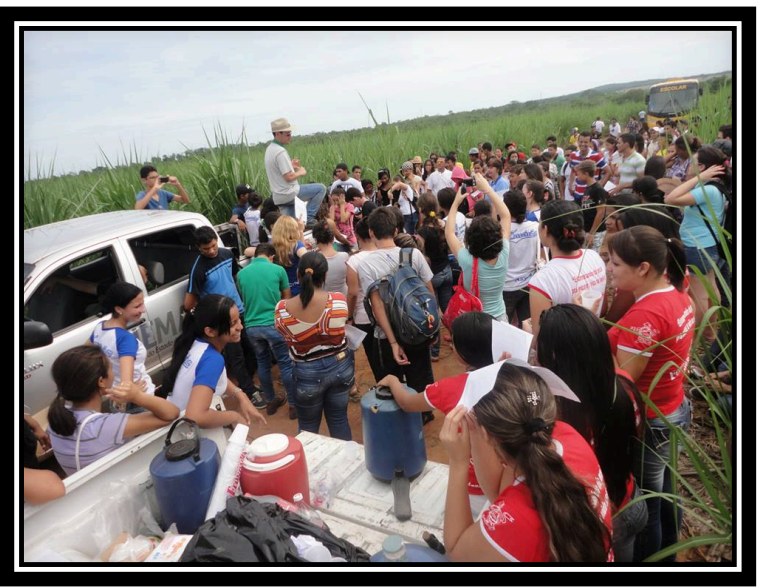

Figura 4 - Professores, acadêmicos e docentes em frente à Caverna Aroé Jarí Chapada dos Guimarães - MT - 16/12/2013

Fonte: Maria Elizabete Rambo Kocchann, Acervo particular, 2013. 
Revista Tecné, Episteme y Didaxis: TED. Año 2014, Número Extraordinario. ISSN Impreso: 0121-3814, ISSN web: 2323-0126

Memorias, Sexto Congreso Internacional sobre Formación de Profesores de Ciencias. 08 al 10 de octubre de 2014, Bogotá
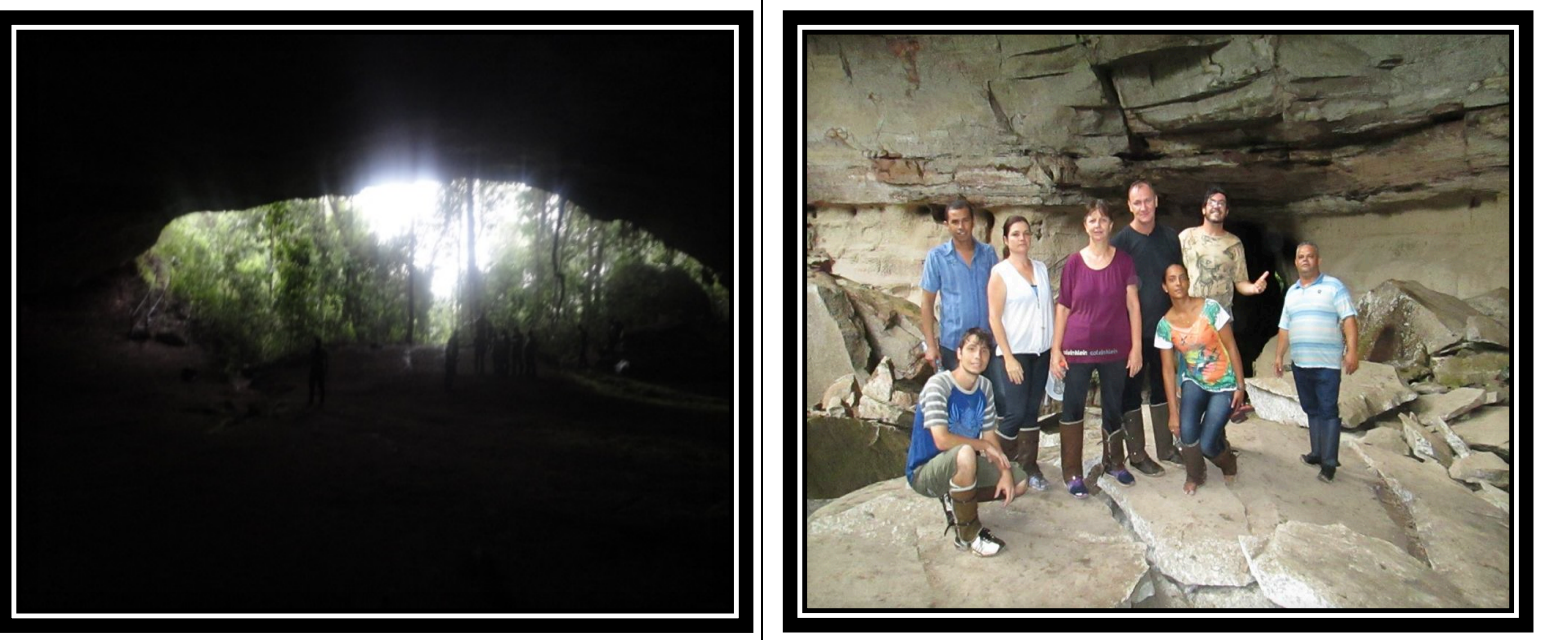

\section{Resultados parciais}

Mesmo sendo um período curto de ações em execução (2013/2 a 2014/1), podemos fazer alguns apontamentos no que concerne aos resultados parciais já visualizados nesse projeto, os quais estão articulados aos subprojetos, em especial aos subprojetos 3 e 4, cujas atividades já foram iniciadas. São eles:

1)os alunos que estiveram no campo perceberam que nas lavouras de soja cujo plantio é feito diretamente, ou seja, sem arar as palhas da safra anterior, há a proteção do meio ambiente;

2)muitos alunos notaram que se as atividades de biologia, química e física fossem feitas em laboratório haveria uma aprendizagens mais efetiva, o que não ocorre nas escolas públicas devido à ausência de laboratórios específicos para tais disciplinas;

3) ao conhecerem a estrutura do laboratório de biologia da UNEMAT - Campus de Tangará da Serra, os alunos ficaram entusiasmados com a infraestrutura do mesmo, principalmente pela diversidade de seres conservados em formol;

4) para muitos alunos, esse projeto propiciará a descoberta da futura profissão.

\section{Conclusões parciais}

Por diferentes motivos, iniciamos o projeto em outubro de 2013. Apesar de serem poucas as atividades realizadas, pudemos perceber que os participantes se 
Revista Tecné, Episteme y Didaxis: TED. Año 2014, Número Extraordinario. ISSN Impreso: 0121-3814, ISSN web: 2323-0126

Memorias, Sexto Congreso Internacional sobre Formación de Profesores de Ciencias. 08 al 10 de octubre de 2014, Bogotá

mostraram interessados, questionadores, curiosos, além de ressaltarem a necessidade de se intensificarem as ações de aproximação entre a universidade e a escola.

Destacamos que as Secretarias de Educação dos municípios são participativas e estão comprometidas com as ações futuras, mesmo sabendo que o trabalho prático também tem seus problemas intrínsecos a sua elaboração.

Sabemos, por fim, que políticas públicas educacionais também têm questões que precisam ser resolvidas no contexto ao qual são aplicadas, mas os impactos e os efeitos dessas ações nas diversas escolas resultará na formação de talentos individuais.

\section{Referências bibliográficas}

Apple, M. Cultural Politics And Education. (1996). Buckingham: Open University Press.

Brasil. Ministério Da Educação. Coordenação De Aperfeiçoamento De Pessoal De Nível Superior - Capes. Acedido Março 10, 2014, Em Http://Capes.Gov.Br/Servicos/Sala-De-Imprensa/Artigos/4721-A-Capes-E-AEducacao-Basica 2011

Brasil. Ministério Da Educação. (2012) Coordenação De Aperfeiçoamento De Pessoal De Nível Superior - Capes. Novos Talentos. Acedido Março 10, 2014, Em Http://Www.Capes.Gov.Br/Educacao-Basica/Novos-Talentos

Xavier, M. E. S. P., Ribeiro, M. L., Noronha, O. (1994). História Da Educação: A Escola No Brasil. São Paulo, Sp: Ftd. 